\title{
Downregulation of tumor protein 53-inducible nuclear protein 1 expression in hepatocellular carcinoma correlates with poor prognosis
}

\author{
YAN DENG ${ }^{1,2}$, AI-MIN LI ${ }^{1}$, XIN-MEI ZHAO ${ }^{1}$, ZHANG-JUAN SONG $^{1}$ and SI-DE LIU ${ }^{1}$ \\ ${ }^{1}$ Department of Gastroenterology, Southern Hospital, Southern Medical University, Guangzhou, Guangdong 510515; \\ ${ }^{2}$ Department of Gastroenterology, Haicang Hospital, Xiamen, Fujian 361000, P.R. China
}

Received July 22, 2015; Accepted November 7, 2016

DOI: $10.3892 / \mathrm{ol} .2016 .5537$

\begin{abstract}
The expression of tumor protein 53-inducible nuclear protein 1 (TP53INP1) is upregulated in certain cancers and downregulated in others. However, its expression in hepatocellular carcinoma (HCC) is not clear. The present study aimed to investigate the expression and prognostic value of TP53INP1 and its association with clinicopathological parameters in HCC. TP53INP1 expression in HCC tissue samples was examined via immunohistochemistry, western blotting and reverse transcription-quantitative polymerase chain reaction. Expression was categorized as high or low. The correlations of TP53INP1 expression with clinical characteristics and patients' prognoses were determined. TP53INP1 was frequently decreased in HCC tissues compared with adjacent non-tumorous liver tissues. This decreased expression was significantly associated with American Joint Committee on Cancer stage $(\mathrm{P}=0.014)$ and vascular invasion $(\mathrm{P}=0.024)$. Kaplan-Meier analysis further revealed that recurrence-free survival $(\mathrm{RFS})(\mathrm{P}=0.001)$ and overall survival $(\mathrm{OS})(\mathrm{P}=0.002)$ were significantly worse among patients with low TP53INP1 expression than among those with high TP53INP1 expression. In addition, multivariate analyses revealed that TP53INP1 was an independent predictor of OS [hazard ratio $(\mathrm{HR})=2.680$, $95 \%$ confidence interval $(\mathrm{CI})=1.087-6.608, \mathrm{P}=0.032)$ and RFS $(\mathrm{HR}=2.284,95 \% \mathrm{CI}=1.157-4.511, \mathrm{P}=0.017)$. In conclusion, the expression of TP53INP1 was decreased in HCC, and TP53INP1 downregulation was an independent predictor of poor prognosis in patients with HCC.
\end{abstract}

Correspondence to: Dr Si-De Liu, Department of Gastroenterology, Southern Hospital, Southern Medical University, 1838 North of Guangzhou Avenue, Guangzhou, Guangdong 510515, P.R. China E-mail: liuside2011@163.com

Key words: tumor protein 53-induced nuclear protein 1, hepatocellular carcinoma, prognosis

\section{Introduction}

Tumor protein 53-inducible nuclear protein 1 (TP53INP1) is an apoptotic protein involved in cell stress responses (1). It increases in abundance in response to inflammatory stress and stress-inducing agents such as heat shock, ultraviolet rays, ethanol and mutagens (2-4). TP53INP1 was first identified in a screen of stress-activated pancreatic genes in mice with acute pancreatitis (4). TP53INP1 localizes to human chromosome 8q22 (5) and encodes two nuclear isoforms, TP53INP1 and TP53INP1 $\beta$. Both isoforms are related to homeodomain-interacting protein kinase-2, and regulate p53-mediated transcriptional activation of the p53-inducible gene 3, BCL2-associated X protein and p21 promoters (6).

TP53INP1 expression is downregulated in numerous human cancers, including esophageal carcinomas (7), poorly differentiated stomach adenocarcinomas (8), primary breast carcinomas (9) and pancreatic ductal adenocarcinomas (10). TP53INP1 messenger RNA (mRNA) levels were reduced in $35-59 \%$ of melanoma cell lines compared with melanocytes (11). TP53INP1 expression is enhanced in certain cancers. Ito et al (12) detected elevated TP53INP1 expression in anaplastic thyroid carcinomas, and Giusiano et al (13) reported increased TP53INP1 expression in prostate cancers. The reason why TP53INP1 is upregulated in certain cancers and downregulated in others is not clear. In addition, its expression and prognostic value in hepatocellular carcinoma (HCC) have not been reported to date.

HCC is one of the most common cancers in the world (14). It is the third major cause of cancer-associated mortalities (15) and accounts for $75-90 \%$ of all malignant tumors in adult livers (16). The aim of the present study was to analyze the expression patterns of TP53INP1 in a large series of human HCCs in order to i) identify the possible variations of TP53INP1 expression; ii) investigate its correlation with clinicopathological parameters; and iii) evaluate its prognostic value.

\section{Materials and methods}

Patient management and tissue samples. The present study was performed in accordance with the reporting recommendations for tumor marker prognostic studies guidelines (17). The 
institutional ethics committee of Southern Hospital (Guangzhou, China) approved the protocol, and all enrolled subjects provided written informed consent.

Fresh HCC tissue samples and matched adjacent non-tumorous tissues were collected from 65 HCC patients who underwent resection at the Digestive Disease Research Institute of Southern Hospital between March 2008 and March 2011. The enrolled patients i) had a conclusive pathologic diagnosis of HCC; ii) had received curative resection, which was defined as macroscopically complete removal of the tumor; and iii) had available detailed clinicopathological data. Patients were excluded if they had received adjuvant chemotherapy or radiotherapy prior to surgery, or if there was evidence of other malignancies. The detailed clinicopathological characteristics of the HCC patients included in the current study are presented in Table I.

Patients were followed up until August 31, 2014. Among the 65 patients, $9(13.8 \%)$ were lost to follow-up. Tumor recurrence confirmation was based on typical appearances on magnetic resonance imaging and/or computed tomography scans, as well as elevated $\alpha$-fetoprotein protein (AFP) levels. The median follow-up period was 31 months (range, 1-71 months). Tumor differentiation was based on the criteria proposed by Edmondson and Steiner (18). Tumor stage was defined according to the American Joint Committee on Cancer (AJCC)/International Union against Cancer tumor node metastasis classification system (19).

Immunohistochemistry assay. Immunostaining was performed on 4- $\mu \mathrm{m}$ sections of paraffin-embedded tissue specimens. The sections were deparaffinized with xylene and rehydrated in a graded alcohol series. Antigen retrieval was carried out in a microwave oven in a sodium citrate solution ( $\mathrm{pH}$ 8.0). Endogenous peroxidase was inactivated by incubating the samples in $3 \% \mathrm{H}_{2} \mathrm{O}_{2}$ at room temperature for $20 \mathrm{~min}$. Upon blocking with goat serum (Wuhan Boster Biological Engineering Co., Ltd.) at room temperature for $30 \mathrm{~min}$, the samples were incubated with rabbit polyclonal anti-TP53INP1 antibody (catalog no. AP11890b; 1:50; Abgent, Inc., San Diego, CA, USA) at $4^{\circ} \mathrm{C}$ overnight in a moist chamber. They were then washed thoroughly with PBS and incubated with secondary antibodies (catalog no. HSP0007; 1:200; Shanghai Mjol Biological Technology Co., Ltd.) at $37^{\circ} \mathrm{C}$ for $30 \mathrm{~min}$, conjugated to peroxidase (Beijing Zhongshan Golden Bridge Biotechnology Co., Ltd., Beijing, China). Staining (which was brown-colored) was visualized using a 3,3'-diaminobenzidine kit (Zhongshan Golden Bridge Biotechnology Co., Ltd.). Upon counterstaining with hematoxylin, the samples were dehydrated in a graded alcohol series and mounted. Negative controls were prepared in the absence of primary antibody.

Immunohistochemical staining was evaluated by two independent observers who were blinded to the clinical data. Concordance was achieved in $94 \%$ of the cases, and disagreements were resolved by consensus (20). Each sample was scored according to the intensity of the staining (no staining $=0$, weak staining $=1$, moderate staining $=2$ and strong staining=3) and the percentage of stained cells $(<5 \%=0,5-25 \%=1,26-50 \%=2$, $51-75 \%=3$ and $76-100 \%=4)$. The percentage of cells at each intensity was multiplied by the corresponding intensity value to obtain an immunostaining score ranging from 0 to 12 . The scores were combined to obtain an overall mean score. Using
Table I. Clinicopathological features of 65 patients with hepatocellular carcinoma.

\begin{tabular}{|c|c|}
\hline Variables & Value \\
\hline Median age (range), years & $49.9(18-83)$ \\
\hline \multicolumn{2}{|l|}{ Gender, $\mathrm{n}$} \\
\hline Male & 59 \\
\hline Female & 6 \\
\hline \multicolumn{2}{|l|}{ HBsAg expression, $n$} \\
\hline Positive & 56 \\
\hline Negative & 9 \\
\hline \multicolumn{2}{|l|}{ AFP levels, $n$} \\
\hline$>400 \mathrm{ng} / \mathrm{ml}$ & 30 \\
\hline$\leq 400 \mathrm{ng} / \mathrm{ml}$ & 35 \\
\hline \multicolumn{2}{|l|}{ Liver cirrhosis, $\mathrm{n}$} \\
\hline Absent & 40 \\
\hline Present & 25 \\
\hline \multicolumn{2}{|l|}{ Vascular invasion, $\mathrm{n}$} \\
\hline Absent & 11 \\
\hline Present & 54 \\
\hline \multicolumn{2}{|l|}{ Intrahepatic metastasis, $\mathrm{n}$} \\
\hline Absent & 53 \\
\hline Present & 12 \\
\hline \multicolumn{2}{|l|}{ Tumor size, $\mathrm{n}$} \\
\hline$\leq 5 \mathrm{~cm}$ & 23 \\
\hline$>5 \mathrm{~cm}$ & 42 \\
\hline \multicolumn{2}{|l|}{ Tumor number, $\mathrm{n}$} \\
\hline Single & 55 \\
\hline Multiple & 10 \\
\hline \multicolumn{2}{|l|}{ Tumor differentiation, $\mathrm{n}$} \\
\hline Well & 23 \\
\hline Moderate & 31 \\
\hline Poor & 11 \\
\hline \multicolumn{2}{|l|}{ AJCC stage, $n$} \\
\hline $\mathrm{I} / \mathrm{II}$ & 56 \\
\hline III/IV & 9 \\
\hline
\end{tabular}

HBsAg, hepatitis B surface antigen; AFP, $\alpha$-fetoprotein; AJCC, American Joint Committee on Cancer.

this assessment system, the optimal cutoff values were as follows: 0-3 (low) and 4-12 (high).

Western blot analysis. Proteins were extracted in radioimmunoprecipitation buffer (EMD Millipore, Billerica, MA, USA). Protein concentration was determined using a Pierce BCA Protein Assay kit (Thermo Fisher Scientific, Inc., Waltham, MA, USA). Samples with equal amounts of total protein were separated on $12 \%$ SDS-PAGE and electrotransferred to polyvinylidene difluoride membranes (Bio-Rad Laboratories, Inc., Hercules, CA, USA). Upon blocking in TBS/Tween-20 containing 5\% non-fat milk powder at room temperature for $5 \mathrm{~min}$ with agitation, the membranes were incubated for $1 \mathrm{~h}$ with anti-TP53INP1 rabbit 
A

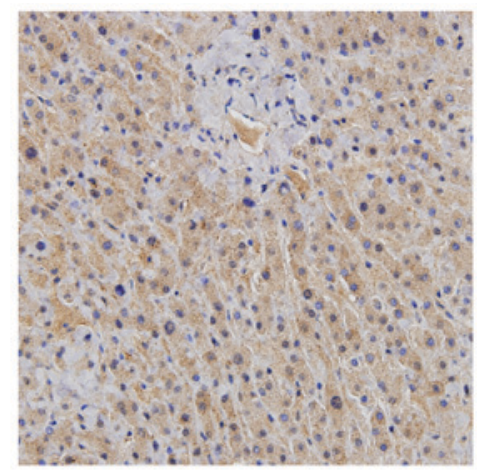

C

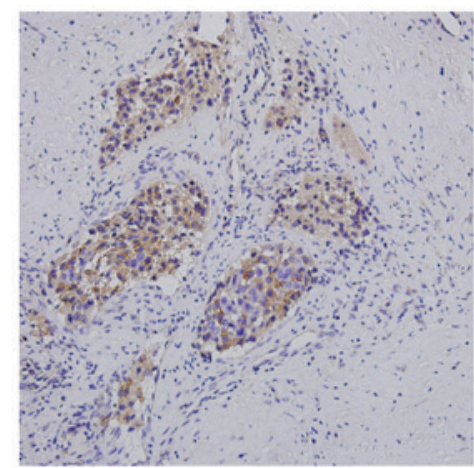

B

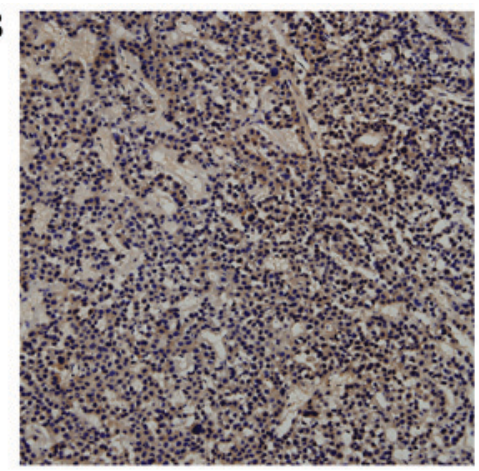

D

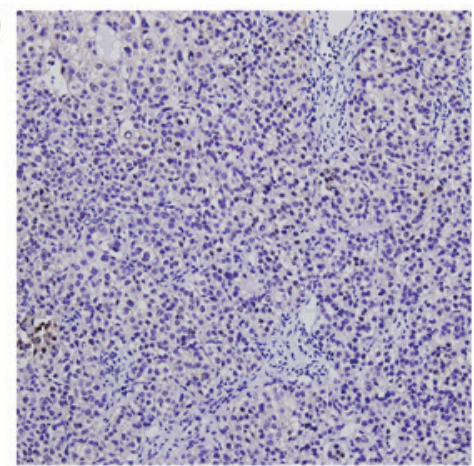

Figure 1. Immunohistochemical analysis of TP53INP1 expression in HCC. (A) TP53INP1 was strongly expressed in adjacent non-tumorous liver tissues (magnification, x200). TP53INP1 expression decreased in (B) well (magnification, x200), (C) moderately (magnification, x200) and (D) poorly differentiated HCC tissues (magnification, x200).

polyclonal antibody (catalog no. AP11890b; 1:250; Abgent, Inc.) and anti- $\beta$-actin mouse monoclonal antibody (catalog no. CW0096; 1:1,000; Beijing Zhongshan Golden Bridge Biotechnology Co., Ltd.) at $4^{\circ} \mathrm{C}$ overnight. Upon incubation of the membranes with secondary antibodies (catalog no. HSP0007; 1:200; Shanghai Mjol Biological Technology Co., Ltd.) at room temperature for $3 \mathrm{~h}$, immunoreactive bands were visualized by enhanced chemilumiscence using a GeneGnome HR Bioimaging System (Syngene, Frederick, MD, USA).

Reverse transcription-quantitative polymerase chain reaction (RT-qPCR) analysis. Total RNA was extracted from tissues using TRIzol (Invitrogen; Thermo Fisher Scientific, Inc.), and complementary DNA libraries were generated from total RNA using a High-Capacity cDNA Archive kit according to the manufacturer's protocol (Applied Biosystems; Thermo Fisher Scientific, Inc.). RT-qPCR was performed in triplicate using the SYBR-Green system on a LightCycler 480 Real-Time PCR System (Roche Diagnostics GmbH, Mannheim, Germany). Relative mRNA levels were calculated according to the quantification cycle $(\mathrm{Cq})$ values corrected for GAPDH expression using the $2^{-\Delta \Delta C \mathrm{q}}$ method as follows: $\Delta \Delta \mathrm{Cq}=\Delta \mathrm{Cq}$ (treatment) $-\Delta \mathrm{Cq}$ (control) or $\Delta \mathrm{Cq}=\mathrm{Cq}$ (target genes)- $\mathrm{Cq}$ (GAPDH). The primer sequences were as follows: TP53INP1, 5'-GCACCCTTCAGT CTTTTCCTGTT-3' (forward) and 5'-GAGAAAGCAGGA ATCACTTGTATC-3' (reverse); and GAPDH, 5'-GAAGGT GAAGGTCGGAGT-3' (forward) and 5'-GAAGATGGTGAT GGGATTTC-3' (reverse).

Statistical analysis. All statistical analyses were carried out using SPSS version 13.0 software (SPSS, Inc., Chicago, IL, USA). Differences between two independent groups were analyzed using the Student's $t$-test. The clinicopathological features of HCC were analyzed using the Pearson's $\chi^{2}$ test. Recurrence-free survival (RFS) and overall survival (OS) were calculated using the Kaplan-Meier method, and significance was assessed using the log-rank test. RFS was defined as the interval between the date of surgery and the date of detection of a recurrent tumor. OS was defined as the interval between the date of surgery and the date of mortality or last follow-up. Independent prognostic factors for OS and RFS were identified using the Cox proportional hazards regression model. Data are presented as the mean \pm standard error of the mean. $\mathrm{P}<0.05$ was considered to indicate a statistically significant difference.

\section{Results}

TP53INP1 expression is downregulated in HCC tissues. TP53INP1 expression was significantly decreased in HCC tissues compared with adjacent non-tumorous tissues, as determined via western blotting and immunohistochemistry. TP53INP1 was predominantly localized in the cytoplasm of hepatic cells, with little staining was present in the nuclei, as visualized via immunohistochemistry. Heavy TP53INP1 staining was observed in the epithelial cells in normal-appearing mucosa adjacent to HCC cells, whereas TP53INP1 staining in HCC cells was faint or absent (Fig. 1). In western blot analyses, TP53INP1 expression was lower in 8 of 9 HCC tissue samples than in matched adjacent non-tumorous tissue (Fig. 2).

To further examine TP53INP1 expression, several sample sets were analyzed via RT-qPCR. Notably, TP53INP1 mRNA expression was significantly lower in HCC tissues $(0.4103 \pm 0.03674)$ than in adjacent non-tumorous tissues (0.6851 $\pm 0.05825, \mathrm{P}=0.0001)$ (Fig. 3). 
Table II. Association of TP53INP1 messenger RNA expression with clinicopathological characteristics of 65 patients with hepatocellular carcinoma.

TP53INP1 expression

\begin{tabular}{|c|c|c|c|c|}
\hline & & & & \\
\hline Variables & Patients, $\mathrm{n}$ & Low $(n=32)$ & High $(n=33)$ & P-value \\
\hline Age, years & & & & 0.897 \\
\hline$<50$ & 34 & 17 & 17 & \\
\hline$\geq 50$ & 31 & 15 & 16 & \\
\hline Gender & & & & 0.968 \\
\hline Male & 59 & 29 & 30 & \\
\hline Female & 6 & 3 & 3 & \\
\hline HBsAg expression & & & & 0.304 \\
\hline Positive & 56 & 29 & 27 & \\
\hline Negative & 9 & 3 & 6 & \\
\hline AFP levels, $\mathrm{ng} / \mathrm{ml}$ & & & & 0.702 \\
\hline$>400$ & 30 & 16 & 14 & \\
\hline$\leq 400$ & 35 & 18 & 17 & \\
\hline Liver cirrhosis & & & & 0.875 \\
\hline Absent & 25 & 12 & 13 & \\
\hline Present & 40 & 20 & 20 & \\
\hline Vascular invasion & & & & 0.024 \\
\hline Absent & 11 & 2 & 9 & \\
\hline Present & 54 & 30 & 24 & \\
\hline Intrahepatic metastasis & & & & 0.223 \\
\hline Absent & 53 & 28 & 25 & \\
\hline Present & 12 & 8 & 4 & \\
\hline Tumor size, $\mathrm{cm}$ & & & & 0.056 \\
\hline$\leq 5$ & 23 & 15 & 8 & \\
\hline$>5$ & 42 & 17 & 25 & \\
\hline Tumor number & & & & 0.110 \\
\hline Single & 54 & 29 & 25 & \\
\hline Multiple & 42 & 17 & 25 & \\
\hline Tumor differentiation & & & & 0.644 \\
\hline Well & 23 & 12 & 11 & \\
\hline Moderate & 31 & 16 & 15 & \\
\hline Poor & 11 & 4 & 7 & \\
\hline AJCC stage & & & & 0.014 \\
\hline $\mathrm{I} / \mathrm{II}$ & 56 & 31 & 25 & \\
\hline III/IV & 9 & 1 & 8 & \\
\hline
\end{tabular}

HBsAg, hepatitis B surface antigen; AFP, $\alpha$-fetoprotein; AJCC, American Joint Committee on Cancer; TP53INP1, tumor protein 53-induced nuclear protein 1 .

Expression of TP53INP1 and its clinicopathological relevance in hepatic tissues. To investigate the significance of TP53INP expression in HCC, the association between TP53INP mRNA levels and the clinicopathological characteristics of $65 \mathrm{HCC}$ patients were evaluated in the present study. TP53INP1 mRNA expression was categorized as high or low. As shown in Table II, low expression of TP53INP1 mRNA closely correlated with AJCC stage $(\mathrm{P}=0.014)$ and vascular invasion $(P=0.024)$. There were no significant differences in other clinical characteristics between the high and low expression groups.

Low expression of TP53INP1 predicts poor prognosis in HCC patients. The potential association between TP53INP1 expression and survival (RFS and OS) was retrospectively evaluated via Kaplan-Meier analysis. RFS (Fig. 4A) and OS (Fig. 4B) were significantly worse in HCC patients expressing low TP53INP1 levels compared with those expressing high TP53INP1 levels, 
Table III. Univariate analysis of factors associated with RFS and OS in patients with hepatocellular carcinoma.

\begin{tabular}{|c|c|c|c|c|}
\hline \multirow[b]{2}{*}{ Variables } & \multicolumn{2}{|l|}{ RFS } & \multicolumn{2}{|l|}{ OS } \\
\hline & $\mathrm{HR}(95 \% \mathrm{CI})$ & P-value & HR $(95 \% \mathrm{CI})$ & P-value \\
\hline Age, years $(<50$ vs. $\geq 50)$ & $1.111(0.600-2.059)$ & 0.737 & $0.667(0.310-1.438)$ & 0.302 \\
\hline Gender (male vs. female) & $1.200(0.468-3.075)$ & 0.704 & $1.223(0.368-4.067)$ & 0.743 \\
\hline HBsAg expression (negative vs. positive) & $1.420(0.555-3.632)$ & 0.464 & $1.656(0.498-5.505)$ & 0.411 \\
\hline AFP levels, ng/ml ( $\leq 400$ vs. $>400)$ & $1.816(0.972-3.391)$ & 0.061 & $2.812(1.281-6.169)$ & 0.010 \\
\hline Liver cirrhosis (absent vs. present) & $0.902(0.478-1.703)$ & 0.751 & $1.118(0.512-2.442)$ & 0.780 \\
\hline Vascular invasion (absent vs. present) & $3.004(1.416-6.373)$ & 0.004 & $4.275(1.848-9.889)$ & 0.001 \\
\hline Intrahepatic metastasis (absent vs. present) & $1.833(0.895-3.753)$ & 0.098 & $1.759(0.709-4.363)$ & 0.223 \\
\hline Tumor size, $\mathrm{cm}(\leq 5 \mathrm{vs.}>5)$ & $1.447(0.737-2.841)$ & 0.283 & $1.377(0.602-3.150)$ & 0.448 \\
\hline Tumor number (single vs. multiple) & $1.729(0.821-3.641)$ & 0.150 & $1.744(0.702-4.328)$ & 0.231 \\
\hline Differentiation (poor/moderate vs. well) & $0.521(0.338-0.801)$ & 0.003 & $0.432(0.251-0.744)$ & 0.002 \\
\hline AJCC stage (I/II vs. III/IV) & $2.224(1.016-4.869)$ & 0.045 & $2.943(1.182-7.327)$ & 0.020 \\
\hline TP53INP1 expression (low vs. high) & $2.604(1.345-5.039)$ & 0.005 & $3.403(1.436-8.063)$ & 0.005 \\
\hline
\end{tabular}

RFS, recurrence-free survival; OS, overall survival; HR, hazard ratio; CI, confidence interval; HBsAg, hepatitis B surface antigen; AFP, $\alpha$-fetoprotein; AJCC, American Joint Committee on Cancer; TP53INP1, tumor protein 53-induced nuclear protein 1.

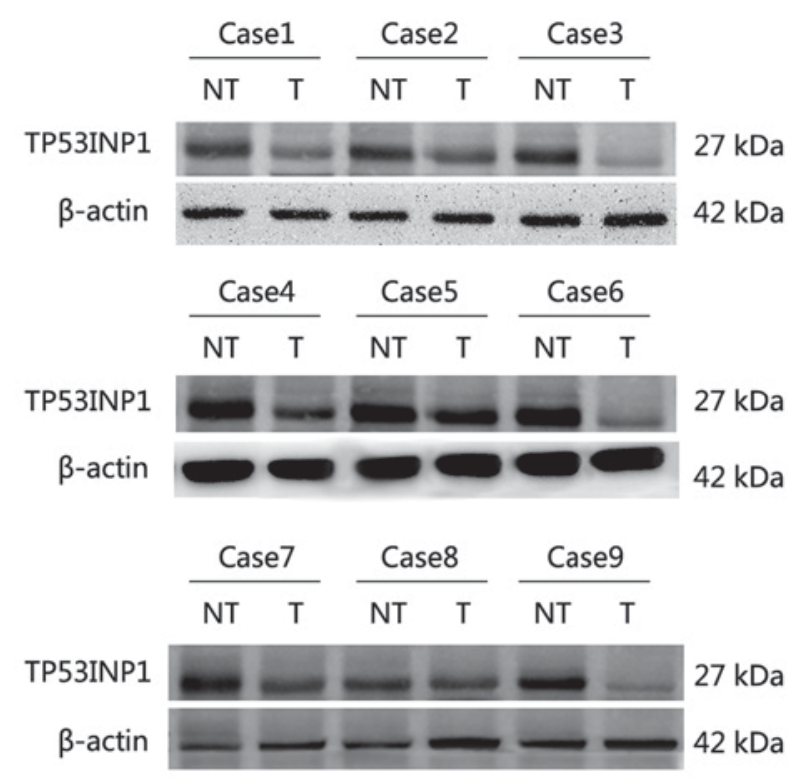

Figure 2. TP53INP1 protein expression was detected in nine paired hepatocellular carcinoma tissues and matched adjacent non-tumorous tissues by western blotting. T, tumorous; NT, non-tumorous; TP53INP1, tumor protein 53 -induced nuclear protein 1.

with median survival times of 10 and 38 months, respectively $(\mathrm{P}=0.003)$.

Twelve clinicopathological variables were included in a univariate analysis, including age, gender, serum hepatitis B surface antigen (HBsAg) levels, serum AFP levels, liver cirrhosis, vessel invasion, intrahepatic metastasis, tumor size, tumor number, tumor differentiation, AJCC stage and TP53INP1 expression. Of these, tumor differentiation, AJCC stage, vascular invasion and TP53INP1 expression were significant prognostic factors of RFS and OS in univariate analysis (Table III). In addition, multivariate analysis (Table IV) revealed that TP53INP1

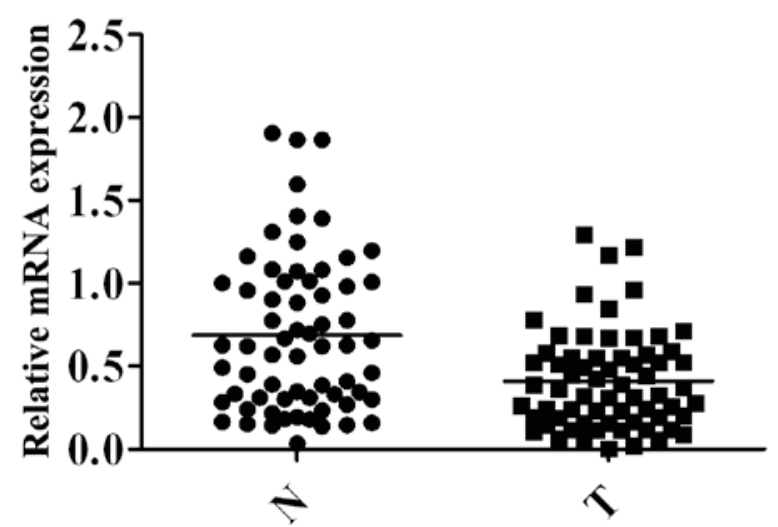

Figure 3. Relative messenger RNA expression of tumor protein 53-induced nuclear protein 1 in hepatocellular carcinoma tissues was decreased compared with that in matched adjacent non-tumorous tissues, as determined by reverse transcription-quantitative polymerase chain reaction $(n=65$, $\mathrm{P}<0.001)$. T, tumor; $\mathrm{N}$, normal.

was also an independent prognostic factor for both RFS [hazard ratio $(\mathrm{HR})=2.284,95 \%$ confidence interval $(\mathrm{CI})=1.157-4.511$, $\mathrm{P}=0.017]$ and $\mathrm{OS}(\mathrm{HR}=2.680,95 \% \mathrm{CI}=1.087-6.608, \mathrm{P}=0.032)$ (Table III). Thus, low expression of TP53INP1 may serve as a prognostic indicator for patients with HCC.

\section{Discussion}

TP53INP1 is a stress-induced protein that serves a role in p53-mediated apoptosis and cell cycle arrest $(2,4,21)$. Its expression is downregulated in stomach (8), pancreatic (10) and inflammation-mediated colic carcinomas (22), but upregulated in medullary thyroid carcinomas (23) and prostate cancers (24). Therefore, it is possible that TP53INP1 can act either as a tumor suppressor or an oncoprotein depending on the tumor microenvironment or the tissue type. To date, 
Table IV. Multivariate analysis of factors associated with RFS and OS in patients with hepatocellular carcinoma.

\begin{tabular}{|c|c|c|c|c|}
\hline \multirow[b]{2}{*}{ Variables } & \multicolumn{2}{|l|}{ RFS } & \multicolumn{2}{|l|}{ OS } \\
\hline & HR $(95 \% \mathrm{CI})$ & P-value & $\mathrm{HR}(95 \% \mathrm{CI})$ & P-value \\
\hline Age, years (<50 vs. $\geq 50)$ & $2.063(0.971-4.387)$ & 0.060 & $1.227(0.499-3.017)$ & 0.656 \\
\hline Gender (male vs. female) & $1.500(0.468-4.802)$ & 0.495 & $1.635(0.400-6.674)$ & 0.493 \\
\hline HBsAg expression (negative vs. positive) & $1.833(0.561-5.994)$ & 0.316 & $1.565(0.375-6.537)$ & 0.539 \\
\hline AFP levels, ng/ml ( $\leq 400$ vs. $>400)$ & $1.587(0.838-3.004)$ & 0.156 & $2.512(1.135-5.560)$ & 0.023 \\
\hline Liver cirrhosis (absent vs. present) & $1.060(0.419-2.681)$ & 0.902 & $1.398(0.460-4.248)$ & 0.554 \\
\hline Vascular invasion (absent vs. present) & $2.310(1.065-5.012)$ & 0.034 & $2.841(1.172-6.884)$ & 0.021 \\
\hline Intrahepatic metastasis (absent vs. present) & $2.043(0.558-7.482)$ & 0.281 & $1.842(0.379-8.944)$ & 0.449 \\
\hline Tumor size, $\mathrm{cm}(\leq 5$ vs. $>5)$ & $2.214(0.839-5.839)$ & 0.108 & $1.889(0.589-6.064)$ & 0.285 \\
\hline Tumor number (single vs. multiple) & $1.354(0.462-3.967)$ & 0.580 & $1.350(0.388-4.697)$ & 0.637 \\
\hline Differentiation (poor/moderate vs. well) & $1.584(0.575-4.236)$ & 0.672 & $1.736(0.458-5.872)$ & 0.413 \\
\hline AJCC stage (I/II vs. III/IV) & $0.695(0.220-2.199)$ & 0.536 & $0.867(0.219-3.438)$ & 0.839 \\
\hline TP53INP1 expression (low vs. high) & $2.284(1.157-4.511)$ & 0.017 & $2.680(1.087-6.608)$ & 0.032 \\
\hline
\end{tabular}

RFS, recurrence-free survival; OS, overall survival; HR, hazard ratio; CI, confidence interval; HBsAg, hepatitis B surface antigen; AFP, $\alpha$-fetoprotein; AJCC, American Joint Committee on Cancer; TP53INP1, tumor protein 53-induced nuclear protein 1.
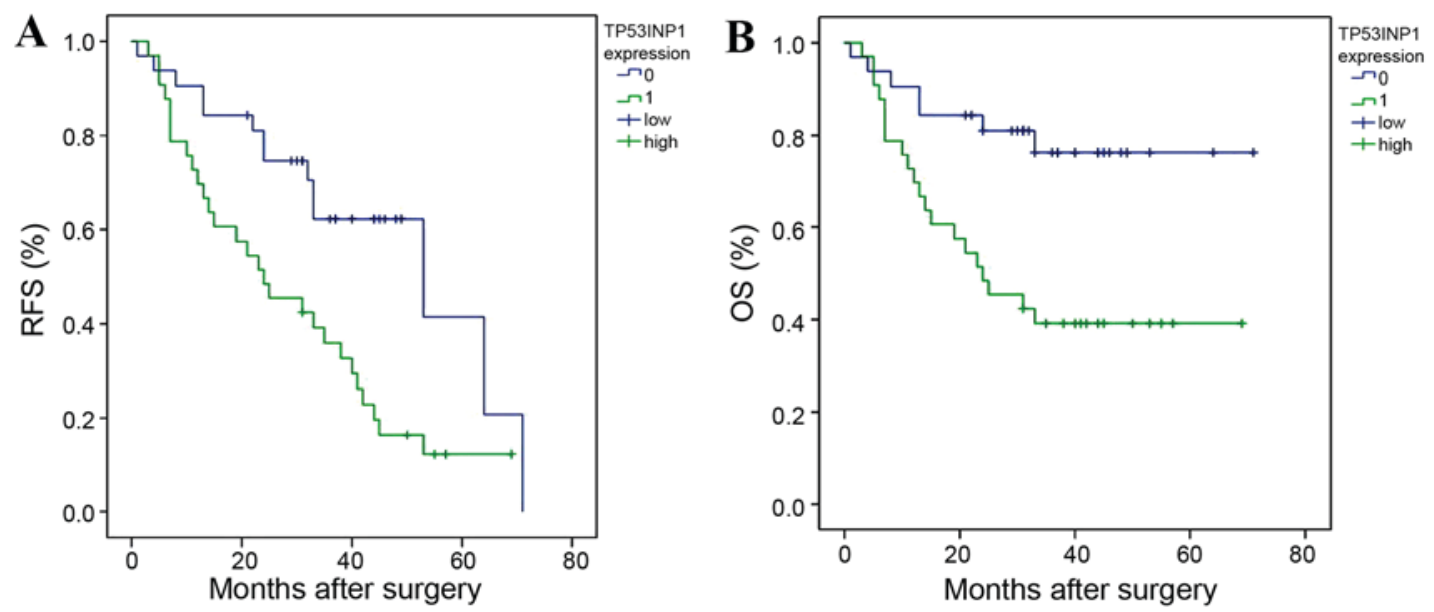

Figure 4. Kaplan-Meier survival curves for (A) RFS and (B) OS in patients with hepatocellular carcinoma, according to their TP53INP1 expression levels. Blue, patients with low TP53INP1 expression; green, patients with high TP53INP1 expression; TP53INP1, tumor protein 53-induced nuclear protein 1.

TP53INP1 expression and its prognostic value in HCC have been unclear.

The present study systematically examined the expression of TP53INP1 in HCC tissue samples. TP53INP1 protein levels were measured via western blotting and immunohistochemistry, and TP53INP1 mRNA levels were quantitated via RT-qPCR. All analyses revealed significantly lower expression of TP53INP1 in HCC tissue samples than in paired samples of non-tumorous adjacent regions. To the best of our knowledge, the present study is the first to report TP53INP1 downregulation in HCC.

TP53INP1 expression is high in HCC adjacent non-tumorous tissues and low in HCC tissue, suggesting that loss of TP53INP1 maybe contribute to HCC progression. Seux et al (25) observed that TP53INP1 silencing increased the migration of mouse embryonic fibroblasts and pancreatic cancer cells. Seillier et al (26) demonstrated that TP53INP1 interacted with autophagy-related 8 proteins to induce autophagy-dependent cell death in U2OS cells. Future studies should focus on clarifying the mechanisms of TP53INP1 expression in HCC.

Jiang et al (8) reported that reductions in TP53INP1 expression in gastric adenocarcinomas were associated with poor prognosis. Conversely, Giusiano et al (24) observed that TP53INP1 overexpression was an unfavorable prognostic factor in prostate cancer. The present study is the first to reveal a positive impact of TP53INP1 expression on survival in HCC. In addition to confirming that the expression of TP53INP1 was downregulated in HCC tissues, the present results further revealed that low TP53INP1 expression significantly correlated with advanced AJCC stage and vascular invasion, and that decreased expression of TP53INP1 predicted poor prognosis in patients with HCC following hepatectomy. Lastly, TP53INP1 expression was a prognostic indicator of RFS and OS, independently of other clinicopathological variables, in a multivariate analysis. 
In conclusion, the present study identified for the first time the downregulation of TP53INP1 in human HCC tissues, which was closely associated with AJCC stage and vascular invasion in patients with HCC. Our findings also suggest that low expression of TP53INP1 may serve as a potent prognostic marker for patients with HCC.

\section{References}

1. Ringer L, Sirajuddin P, Tricoli L, Waye S, Choudhry MU, Parasido E, Sivakumar A, Heckler M, Naeem A, Abdelgawad I, et al: The induction of the p53 tumor suppressor protein bridges the apoptotic and autophagic signaling pathways to regulate cell death in prostate cancer cells. Oncotarget 5: 10678-10691, 2014

2. Okamura S, Arakawa H, Tanaka T, Nakanishi H, Ng CC, Taya Y, Monden M and Nakamura Y: p53DINP1, a p53-inducible gene, regulates p53-dependent apoptosis. Mol Cell 8: 85-94, 2001.

3. Tomasini R, Samir AA, Pebusque MJ, Calvo EL, Totaro S, Dagorn JC, Dusetti NJ and Iovanna JL: P53-dependent expression of the stress-induced protein (SIP). Eur J Cell Biol 81: 294-301, 2002

4. Tomasini R, Samir AA, Vaccaro MI, Pebusque MJ, Dagorn JC, Iovanna JL and Dusetti NJ: Molecular and functional characterization of the stress-induced protein (SIP) gene and its two transcripts generated by alternative splicing. SIP induced by stress and promotes cell death. J Biol Chem 276: 44185-44192, 2001.

5. Nowak J, Depetris D, Iovanna JL, Mattei MG and Pebusque MJ: Assignment of the tumor protein p53 induced nuclear protein 2 (TP53INP2) gene to human chromosome band 20q11.2 by in situ hybridization. Cytogenet Genome Res 108: 362, 2005.

6. Tomasini R, Samir AA, Carrier A, Isnardon D, Cecchinelli B, Soddu S, Malissen B, Dagorn JC, Iovanna JL and Dusetti NJ: TP53INP1s and homeodomain-interacting protein kinase-2 (HIPK2) are partners in regulating p53 activity. J Biol Chem 278: 37722-37729, 2003.

7. Weng W, Yang Q, Huang M, Qiao Y, Xie Y, Yu Y, Jing A and Li Z: c-Myc inhibits TP53INP1 expression via promoter methylation in esophageal carcinoma. Biochem Biophys Res Commun 405: 278-284, 2011.

8. Jiang PH, Motoo Y, Garcia S, Iovanna JL, Pébusque MJ and Sawabu N: Down-expression of tumor protein p53-induced nuclear protein 1 in human gastric cancer. World J Gastroenterol 12: 691-696, 2006.

9. Ito Y, Motoo Y, Yoshida H, Iovanna JL, Takamura Y, Miya A, Kuma K and Miyauchi A: Decreased expression of tumor protein p53-induced nuclear protein 1 (TP53INP1) in breast carcinoma. Anticancer Res 26: 4391-4395, 2006.

10. Gironella M, Seux M, Xie MJ, Cano C, Tomasini R, Gommeaux J, Garcia S, Nowak J, Yeung ML, Jeang KT, et al: Tumor protein 53 -induced nuclear protein 1 expression is repressed by miR-155, and its restoration inhibits pancreatic tumor development. Proc Natl Acad Sci USA 104: 16170-16175, 2007.

11. Bonazzi VF, Irwin D and Hayward NK: Identification of candidate tumor suppressor genes inactivated by promoter methylation in melanoma. Genes Chromosomes Cancer 48 $10-21,2009$.
12. Ito Y, Motoo Y, Yoshida H, Iovanna JL, Nakamura Y, Kuma K and Miyauchi A: High level of tumour protein p53-induced nuclear protein 1 (TP53INP1) expression in anaplastic carcinoma of the thyroid. Pathology 38: 545-547, 2006.

13. Giusiano S, Baylot V, Andrieu C, Fazli L, Gleave M, Iovanna JL, Taranger-Charpin C, Garcia S and Rocchi P: TP53INP1 as new therapeutic target in castration-resistant prostate cancer. Prostate 72: 1286-1294, 2012.

14. Li WG and Wang HQ: Inhibitory effects of Silibinin combined with doxorubicin in hepatocellular carcinoma; an in vivo study. J BUON 21: 917-924, 2016.

15. Ferlay J, Shin HR, Bray F, Forman D, Mathers C and Parkin DM: Estimates of worldwide burden of cancer in 2008: GLOBOCAN 2008. Int J Cancer 127: 2893-2917, 2010.

16. Center MM and Jemal A: International trends in liver cancer incidence rates. Cancer Epidemiol Biomarkers Prev 20: 2362-2368, 2011.

17. European association for the study of the liver; European organisation for research and treatment of cancer: EASL-EORTC clinical practice guidelines: Management of hepatocellular carcinoma. J Hepatol 56: 908-943, 2012.

18. Edmondson HA and Steiner PE: Primary carcinoma of the liver: A study of 100 cases among 48,900 necropsies. Cancer 7: 462-503, 1954.

19. Edge SB and Compton CC: The American Joint Committee on Cancer: The 7th edition of the AJCC cancer staging manual and the future of TNM. Ann Surg Oncol 17: 1471-1474, 2010.

20. Pinder SE, Brown JP, Gillett C, Purdie CA, Speirs V, Thompson AM and Shaaban AM; Translational Subgroup of the NCRI Breast Clinical Studies Group: The manufacture and assessment of tissue microarrays: Suggestions and criteria for analysis, with breast cancer as an example. J Clin Pathol 66: 169-177, 2013.

21. Carrier A, Nguyen C, Victorero G, Granjeaud S, Rocha D, Bernard K, Miazek A, Ferrier P, Malissen M, Naquet P, et al: Differential gene expression in CD3epsilon- and RAG1-deficient thymuses: Definition of a set of genes potentially involved in thymocyte maturation. Immunogenetics 50: 255-270, 1999.

22. Gommeaux J, Cano C, Garcia S, Gironella M, Pietri S, Culcasi M, Pébusque MJ, Malissen B, Dusetti N, Iovanna J, et al: Colitis and colitis-associated cancer are exacerbated in mice deficient for tumor protein 53-induced nuclear protein 1. Mol Cell Biol 27: 2215-2228, 2007.

23. Taïeb D, Giusiano S, Sebag F, Marcy M, de Micco C, Palazzo FF, Dusetti NJ, Iovanna JL, Henry JF, Garcia S, et al: Tumor protein p53-induced nuclear protein (TP53INP1) expression in medullary thyroid carcinoma: A molecular guide to the optimal extent of surgery? World J Surg 34: 830-835, 2010.

24. Giusiano S, Garcia S, Andrieu C, Dusetti NJ, Bastide C, Gleave M, Taranger-Charpin C, Iovanna JL and Rocchi P: TP53INP1 overexpression in prostate cancer correlates with poor prognostic factors and is predictive of biological cancer relapse. Prostate 72: 117-128, 2012.

25. Seux M, Peuget S, Montero MP, Siret C, Rigot V, Clerc P, Gigoux V, Pellegrino E, Pouyet L, N'Guessan P, et al: TP53INP1 decreases pancreatic cancer cell migration by regulating SPARC expression. Oncogene 30: 3049-3061, 2011.

26. Seillier M, Peuget S, Gayet O, Gauthier C, N'Guessan P, Monte M, Carrier A, Iovanna JL and Dusetti NJ: TP53INP1, a tumor suppressor, interacts with LC3 and ATG8-family proteins through the LC3-interacting region (LIR) and promotes autophagy-dependent cell death. Cell Death Differ 19: 1525-1535, 2012. 